\title{
Nas malhas da rede com Clarice Lispector... aproximações entre a escrita clariceana e a escrita na TAR
}

\section{In the meshes of the network with Clarice Lispector... approaches between Clarice's writings and the writings in ANT}

\section{En las Mallas de la Red con Clarice Lispector... similitudes entre los escritos de Clarice e os escritos en la TAR}

\section{Débora Emanuelle Nascimento Lomba*}

Universidade do Estado do Rio de Janeiro - UERJ, Rio de Janeiro, Rio de Janeiro, Brasil

\section{Laura Cristina de Toledo Quadros**}

Universidade do Estado do Rio de Janeiro - UERJ, Rio de Janeiro, Rio de Janeiro, Brasil

\section{Luciana Loyola Madeira Soares***}

Instituto Brasileiro de Medicina de Reabilitação - IBMR, Rio de Janeiro, Rio de Janeiro, Brasil

\begin{abstract}
RESUMO
Neste artigo pretendemos trazer ditos e escritos de Clarice Lispector para uma interlocução com a Teoria Ator-Rede (TAR), de Bruno Latour. Em nossos encontros, formais ou informais na UERJ, percebemos que com frequência a esta escritora recorremos nas referências e ilustrações ao estudo da TAR a que temos nos dedicado na pós-graduação em Psicologia Social (PPGPS). De acordo com a própria Clarice, não tivemos a presunção de explicá-la ou interpretá-la - apenas segui-la e explicitar as conexões com o que faz pesquisador da TAR ao compor seu texto. Dedicamo-nos a ampliar o diálogo entre nós e Clarice, percorrendo prazerosamente os meandros de sua inspiradora escrita através da maneira singular e plena de afetos com que articula atores humanos e não humanos, criando uma relação de intimidade com o leitor.
\end{abstract}

Palavras-chave: Clarice Lispector, TAR, atores humanos e não humanos.

\section{ABSTRACT}

In this paper we intend to bring Clarice Lispector's words and texts to a dialogue with Bruno Latour's Actor-Network Theory (ANT). During our meetings at UERJ we realized that we frequently made a link within Lispector's thoughts and Latour's.We didn't have the intention of giving an explanation neither an interpretation of her writings - we've just followed her steps towards a connection with ANT. It was for us a pleasure to go in search of her paths, to the peculiar and full of feelings way in which she could 
manage human actors and non human actors in an intimate relationship with the reader.

Keywords: Clarice Lispector, ANT, human and non human actors

\begin{abstract}
RESUMEN
En este artículo pretendemos traer palabras y textos de Clarice Lispector para un dialogo con la Teoría Actor-Red (TAR) de Bruno Latour. En nuestros encuentros formales e informales en la UERJ, percibimos que con frecuencia recurrimos a esta escritora para traer referencias e ilustraciones al estudio de la TAR, a la que nos hemos dedicado en el Programa de Pos Graduación en Psicología Social (PPGPS). Estando de acuerdo con la propia Clarice, no tuvimos la intención de explicarla o interpretarla - solamente de seguirla, explicitando las conexiones con la TAR. Nos dedicamos a ampliar nuestro diálogo con Clarice, recorriendo placenteramente los recovecos de sus escritos a través de la singular manera, llena de afectos, con que articula actores humanos y no humanos, creando una relación de intimidad con o lector.
\end{abstract}

Palabras claves: Clarice Lispector, TAR, actores humanos y no humanos

\title{
1 Tecendo fios: nosso encontro com Clarice
}

A proposta desse artigo emergiu de uma delicada confluência de encontros. Partindo de nossa rotina de discussões no grupo de pesquisa entre redes, os quais se desdobraram em agradáveis e produtivos almoços coletivos, descobrimos que em nossos textos havia um ponto comum: todas citávamos ou percorríamos tramas de Clarice Lispector. Coincidência? Afinidade? Sensibilidade? A despeito da alegria da descoberta/revelação, suspeitamos que havia uma aproximação menos inocente ou casual do que nos parecia entre uma escrita e uma atitude clariceana e o modo de praticar uma escrita e uma intervenção em nosso referencial teórico, a Teoria Ator-Rede (TAR). Assim, em torno da mesa onde nos reunimos, Clarice Lispector surge várias vezes como uma inspiradora actante, ao ser lembrada como companheira em nosso estudo na TAR. No entusiasmo vivido a partir do que se desvelava diante de nós, consideramos que Clarice nos apresentava mundos em que a presença de pessoas, coisas, insetos e animais - ou seja, actantes humanos e não humanos guardavam narrativas simétricas, sem protagonismos hierárquicos. Todos pareciam escreverCOM ${ }^{1}$ Clarice. Assim, actantes como Macabéa, a caneta de ouro, a barata ou a galinha Laura ${ }^{2}$ desfiavam belas histórias que nos afetaram de diferentes modos. O que há nessas versões ${ }^{3}$ de mundo costuradas pelas mãos de Clarice e seus actantes, que apoiam nossa compreensão acerca da perspectiva de pesquisar e escrever na TAR?

Sem a pretensão de responder de modo explicativo a essa indagação - o que seria incompatível tanto com Clarice quanto com a TAR seguiremos pelo entrelaçamento dos fios da sensibilidade tecendo 
redes e encontrando conexões com uma metodologia de pesquisa que engendra atores humanos e não humanos em uma escrita que é também uma prática de pesquisa.

$O$ ar que inspiramos ao ler Clarice tem o odor da sensibilidade e a dor do irremediável esforço da criação, que, como ela mesma afirma, de fortuita ou natural nada tem. As páginas da escrita de Clarice têm a cor e a textura de sua experiência de caminhar pelo mundo, vendo, ouvindo, cheirando, saboreando, tateando, respirando, conhecendo-o enquanto cria mundos com o papel, a máquina de escrever, o cigarro e outros actantes. Em suas palavras:

"Eu escrevo para entender melhor o mundo. E acho que escrevendo a gente entende mais um pouquinho do que não escrevendo. É uma lucidez meio nebulosa porque a gente não tem direito consciência dela." (Rocha, 2011, p. 68). Ah... se Clarice soubesse como nos ajuda a escrever... Se não podemos contar a ela, esforçamo-nos para escrever contando com ela: nosso exercício de conhecer 0 mundo. Imediatamente pensamos na lógica do cuidado de A. Mol (2008) que nos propõe uma ação de um cuidar sensível às possibilidades do outro. Quantos actantes tomam parte na escrita! Mortos, ausentes, humanos e não humanos, todos ganham vida e dão vida ao que fazemos ao se articularem na criação de um mundo/tecido, rico em nuances de sensações e imagens que se desdobram em novos mundos produzindo afetações e por elas sendo produzidos.

De imediato, alertamos o leitor que não há em nossa proposta qualquer intenção de adentrar pelo vasto campo literário, com suas peculiaridades e exigências: não o atravessamos, embora ele nos atravesse. Muito mais do que suas obras propriamente ditas, é a escrita singular de Clarice, bem como seu estilo e processo de produção que estão no cerne de nosso interesse. Nos conectamos às suas muitas formas de contemplar e expressar o mundo como ela 0 percebe. Sua leitura de mundo aproxima-se, ao nosso ver, de uma atitude de um pesquisador referenciado na TAR, ou seja, ela não se faz mera observadora; ao contrário, ela se movimenta no que percebe, oferecendo-nos versões de si com o mundo. Dessa forma, parte de nossa interlocução com Clarice é animada também pelas entrevistas que concedeu ao longo de sua trajetória como escritora. Há em suas respostas uma riqueza de impressões, reflexões, indagações que se destacam como costuras em alto relevo. Portanto, o escrever e o descrever se entrelaçam de forma viva, nos trazendo uma Clarice tão íntima quanto estranha. E é nesse nó que se produz nosso encontro: o que Clarice diz em si e por si. E, estudar e produzir tendo a TAR como uma proposta político-metodológica nos permite, 
com muita leveza, abordar o legado e a maneira de dizer que Clarice Lispector demonstra e, pensar algumas aproximações com a proposta da TAR. E, mais do que apenas produzir um artigo científico que aborde esses temas com a mencionada leveza, é nosso intuito escrevê-lo de maneira que fique claro em cada linha de onde falamos, o que pretendemos e, que acreditamos estar produzindo efeitos no leitor. Dito isto, podemos dizer que acabamos de descrever nosso posicionamento político ao escrever este artigo.

Se ousamos aqui tecer aproximações entre os dizeres de Clarice e os textos da TAR, é porque estes últimos nos convocaram a pensar um mundo COM (Moraes, 2010) Clarice e, nesse mundo vivo, encontramo-nos: nós, a escrita e o dizer de Clarice Lispector e a escrita na TAR. Assim, permitimo-nos tal alegoria $e$, ao nos dispormos a expô-la, esperamos que o leitor sinta-se convidado a compartilhar conosco uma dúvida tão enigmática quanto pretensiosa: será que Bruno Latour e seus interlocutores e parceiros leram Lispector?

\section{TAR e Clarice: para além das dicotomias ou "que mundo queremos produzir?"}

Latour introduz no âmbito das ciências uma perspectiva de articulação entre as dicotomias clássicas que predominaram nos modelos científicos dos últimos séculos, considerando a inviabilidade de fragmentar as ordens sem descaracterizá-las por completo.

Assim, a marca primordial que funda o pensamento científico moderno e separa natureza de sociedade, sujeito de objeto, seria uma "ficção" forjada pela necessidade de compreender o mundo a partir de suas relações mecânicas, objetivas e materiais. Esta seria uma pretensão de chegar à essência das "verdades" e, consequentemente, à garantia das certezas onde a ciência seria a legisladora dos modos de organização de um mundo factual, estável, regular, apreensível e explicável.

Embora estejamos ainda apegados ao conforto das certezas que nos permitem "algum" domínio do conhecimento, a evolução da própria ciência aponta para a impossibilidade da primazia de um único método de investigação.

Se considerarmos o contexto das ciências sociais, ficará ainda mais evidente a inadequação de uma metodologia puramente experimental, marcada pela lógica cartesiana para abordar os fenômenos produzidos nesta dinâmica.

Latour $(2000 ; 2004 ;$ 2008) acredita que não há um mundo puramente cartesiano, "arrumado" em sequências ordenadas pela causalidade. Somos "nós" que estabelecemos esta ordem. Será então 
que a busca de leis universais que expliquem e justifiquem os "fatos" ainda deve ser uma tarefa do cientista?

Sob esta ótica, os acontecimentos são movimentos onde objetos e pessoas estão em conexão formando elementos híbridos com uma certa indissociabilidade. Portanto, a ênfase da TAR está nas conexões, articulações, alianças, constituindo redes que produzem formas, relações, deslocamentos impermanentes.

Como devemos estudar estas associações imprevisíveis e heterogêneas que são reveladas pela crescente intensidade das controvérsias? Certamente não por meio de sua separação em 'conhecimento' e 'contexto' ou por sua classificação em 'primitivas' ou 'modernas' ou então por atribuição de graus, indo das 'mais racionais' às 'mais absurdas'. Todas as ações do tipo 'separar', 'classificar', ou 'atribuir graus' não fazem justiça à natureza imprevisível e heterogênea das associações. A única coisa que podemos fazer é observar tudo o que está atado às afirmações (Latour, 2000,p. 331)

Clarice Lispector apresenta em sua obra uma narrativa que a retira de uma lógica linear, levando seu leitor a seguir uma trama onde o eu que chamamos de mundo interno projeta-se no externo nos dando, não raro, uma clara sensação de unidade, de indissociabilidade. Embora a escritora seja tida como introspectiva, a riqueza descritiva de seus textos nos apontam um mundo que não está apenas "lá dentro", mas encarna um mundo revelado pelos olhos da autora e, por que não dizer, por sua forma de estar no mundo. Em entrevista concedida ao jornalista Yllen Kerr ao Jornal do Brasil em 1963, ao ser perguntada se a janela de sua vida é voltada para dentro, Clarice nos brinda com um questionamento e uma reflexão que podemos transportar para nossa discussão em curso. Ela responde:

Se você acha, significaria que olho de fora para dentro? O que significaria que estou dos dois lados. É que o mundo de fora também tem o seu dentro, daí a pergunta, daí os equívocos. 0 mundo de fora também é intimo. Quem o trata com cerimônia e não o mistura a si mesmo, não o vive, e é quem realmente o considera estranho e de fora. A palavra dicotomia é uma das mais secas do dicionário. (Rocha, 2011, p.27, grifo nosso).

Podemos apreciar nessa resposta a noção que Clarice nos traz de um mundo em movimento, constituído pelas práticas que o animam. A noção de uma interioridade tão difundida nas práticas psi, que marca não apenas uma separação entre o sujeito e mundo, como também funda uma subjetividade forjada no segredo (Despret, 2011), é aqui posta em xeque de modo hábil e desafiante. Quando ela destaca 
referindo-se ao "mundo de fora", que "Quem o trata com cerimônia e não o mistura a si mesmo, não o vive, e é quem realmente considera estranho e de fora", nos aproxima da perspectiva dinamizada pela TAR onde o acompanhar o que faz fazer desperta mais interesse do que identificar o por quê se faz fazer. (Latour, 2008). Este mundo em movimento é o que nos interessa. a TAR não busca detectar a mecânica das relações para apreendê-la, mas se interessa pelos processos, pelo que se dá enquanto se dá, são as performances muito mais do que coisas em si que fazem parte do nosso interesse. Como bem nos aponta Clarice: "Quando começam a me fazer muitas perguntas complicadas, me sinto como a centopeia, que um dia the perguntaram como ela não se atrapalhava ao caminhar com cem pés. Ela foi demonstrar sua técnica, e acabou desaprendendo-a. Eu tenho medo disso." (In: Rocha, 2011, p.61). Portanto, ao falarmos a partir do mundo da escrita, indicamos que participamos como escritores ou pesquisadores do engendramento de realidades, de processos de mútua afetação que não são explicáveis, mas que fazem fazer, isto é: máquina de escrever, computador, mortos, animais, que produzem e são produzidos na prática da construção do texto. São descritos, escritos e fazem escrever, adquirindo sentido no corpo do texto e injetando sentido à medida que agem e fazem agir/escrever.

Clarice nos apresenta um mundo conduzido por sua sensibilidade. Em sua escrita, há um espaço para refletir com o outro, humano ou não humano. Há também uma habilidade em nos afetar. Ela escreve ensaisticamente, produzindo conteúdos potentes, muitas vezes autobiográficos, nos quais entrega-se, tecendo ligação forte com o leitor, tentando estabelecer com ele uma interlocução a partir de suas vivências mais singulares, tocando-o de modo sensível. Ler seus escritos é como estar com ela bebendo uma taça de vinho, partilhando confabulações. Clarice apresenta-nos sua noção de mundo encharcada de afetos, que tanto podem ser bem humorados quanto doídos, céticos e esperançosos. Sua escrita não traz qualquer traço de tentativa de estabelecer verdades, conceitos sobre a realidade, tanto que se torna uma autora capaz de pôr literatura e filosofia em fina sintonia. Rica em imagens, a escrita produzida por Clarice valoriza a experiência, tal como no fazer fenomenológico. A partir de relatos tão sutis e finamente desenhados, é possível imaginar e envolver-se, sentir-se afetado pelo que ela nos traz. Portanto, há uma força em sua narrativa que nos desacomoda. E, como contamos o que experienciamos em nossas pesquisas?

Law (2004) e Mol (2007) nos chamam a atenção para a responsabilidade do pesquisador sobre as decisões acerca do que entra e o que fica de fora de sua pesquisa. Tais decisões para esses autores carregam sentidos transformadores e contornam o que Mol (op.cit) nomeia de Política Ontológica. Isso se destaca também na escrita, no momento em que o pesquisador escreve seus relatórios e 
artigos científicos. O modo que ele elege descrever como conduziu e/ou foi conduzido por sua pesquisa constitui-se numa ação viva ou estática de chegar ao outro, podendo excluí-lo ou incluí-lo de várias formas. Retomando a ideia supracitada de que a TAR privilegia acompanhar o que faz fazer, a escolha pelas narrativas vivas, que nos deslocam, provocam sensorialidades e afetos não nos são incomuns; ao contrário, quando aderimos as descrições encarnadas, ou seja, descrever a partir e com o que nos toca enquanto pesquisador, nos comprometemos também com um modo de fazer ciência que transcende as dicotomias e nos confronta diretamente com 0 questionamento levantado por Law (op.cit) que nos provoca a refletir sobre "que mundo queremos produzir" a partir de nossas pesquisas. O mundo produzido por Clarice é um mundo povoado, assim como podem ser nossas pesquisas.

\section{Das vantagens de ser um pesquisador solitário}

Isabelle Stengers (1989), em seu artigo A ciência no feminino, nos conta a história de Barbara McClintock, uma cientista, uma mulher, "considerada uma velha louca incompreensível pela maioria de seus colegas". Como a própria Stengers cita, McClintock era excluída e desprezada por seus colegas, os pesquisadores homens que comandavam o cenário acadêmico, pois seu trabalho se afastava dos moldes tradicionais de se pensar e fazer ciência, o que o caracterizava como um trabalho solitário. E por este caráter solitário e tão divergente do trabalho dos demais pesquisadores denominados por Stengers como caçadores da matilha, é que Clarice Lispector torna-se uma boa interlocutora. Em uma de suas crônicas publicadas no Jornal do Brasil, onde nos convida a pensar sobre as vantagens de ser bobo, Lispector (1999) inicia sua crônica nos dizendo que "O bobo, por não se ocupar com ambições, tem tempo para ver, ouvir e tocar no mundo" (p.310).

Isto nos parece semelhante ao trabalho de Barbara McClintock, uma cientista que se interessou em estudar o milho e conhecê-lo a fundo. E, esta cientista se articula ao milho de uma forma interessada a ouvir o que este tinha a dizer, muito mais do que um interesse em tentar construir generalizações a partir de observações neutras que faz do milho. McClintock buscava em seu trabalho um fazer que não comungava com a lógica dominante do fazer científico, razão esta para a própria Stengers falar de um fazer feminino ao descrever seu trabalho, que assim como o bobo, dedicava tempo para ver, ouvir e tocar no milho. Stengers (1989) descreve McClintock como uma caçadora solitária, em contraposição aos caçadores da matilha, sendo estes os pesquisadores seguidores da epistemologia dominante. 
A autora aponta que "o princípio da matilha é a rapidez", enquanto o caçador solitário evita qualquer precipitação. E mais, ela destaca que os cientistas hoje em dia caçam em matilhas, o que acaba por traduzir uma destruição das singularidades, uma vez que o singular é reduzido ao caso particular de uma regra. E por evitar qualquer precipitação e voltar seu olhar atento a sua "presa", o caçador solitário, assim como o bobo "... tem oportunidade de ver coisas que os espertos não veem." (Lispector, 1999, p.310). Essa é uma delicadeza que reconhecemos na prática da TAR e, embora seja aparentemente simples, exige um desprendimento e uma dedicação ímpares. Além disso, ser solitário muitas vezes nos remete à marginalidade, o que nem sempre nos permite dialogar nos meios acadêmicos. Porém, acreditamos na viabilidade das negociações e, nessas horas, as vantagens de ser bobo podem nos conduzir com certa maestria, uma vez que a despretensão nos permite ocupar espaços onde há menos disputas a serem travadas. $\mathrm{E}$ um espaço uma vez ocupado torna-se um território de encontros que podemos produzir.

Milton Nascimento em 'Bola de meia, bola de gude', poeticamente nos diz que "... o solitário não quer solidão ...". Aproveitamos seu verso para acrescentar que, em TAR, o pesquisador embora tido como solitário, não está sozinho, mas em plena parceria com os pesquisados. Solidária, assim pode ser chamada a atitude do pesquisador na TAR, pois esquiva-se de qualquer traço de assistencialismo e constrói com o outro as questões de seu estudo. As perguntas são assim interessantes por emergirem de um diálogo em que o outro fala por si, numa prática situada, localizada, marcada pela simetria no encontro entre diferentes. Assim também lemos e somos lidos por Clarice; o texto constrói-se à medida que o lemos somos tanto actantes como atuados. Tornamo-nos seus parceiros sem que ela decida por nós o que devemos responder ou entender ao ler seu texto. Este é vividamente produtor de efeitos, portanto, um actante criando novos mundos e versões de realidade.

\section{Clarice e o encontro COM: um retalho costurado à TAR}

Clarice (Rocha, 2011) deixa claro, em sua última entrevista concedida a TV Cultura em 1977, o quanto se incomodava quando a rotulavam, quando a consideravam uma escritora. Segundo ela, receber este rótulo e tamanha formalidade a deixava numa posição isolada. $\mathrm{Na}$ série de crônicas que escreveu para o Jornal do Brasil, Clarice faz interlocuções com seus leitores. Seja respondendo suas cartas, seja escrevendo um novo texto a partir das cartas que recebia com as opiniões destes, o interessante para ela parecia ser a possibilidade de ter uma escrita compartilhada. Embora seu processo de escrita fosse 
acompanhado apenas de seu cigarro e o silêncio das manhãs, sua escrita também era solidária. Fisicamente estava sozinha, mas certamente acompanhada de seus leitores e dos não-humanos, ela compunha um trabalho feito a muitas mãos.

Expresso desta forma, será que nos seria permitido dizer que Clarice tinha em seu campo de escrita muitos atores, que à medida que se agenciavam, escreviam com ela? Apostamos que sim! Sendo assim, mais uma aproximação podemos reconhecer entre a maneira clariceana de escrever e as propostas da Teoria ator-rede: o interesse pelo outro, em compor com este o que se pretende fazer (seja escrever ou pesquisar). Autores da Teoria ator-rede conduzirão suas pesquisas de maneira a pesquisar COM o outro e não sobre o outro. Clarice, no dia 11 de setembro de 1971, escreveu para o Jornal do Brasil a crônica Amor (Lispector, 1999, p. 374-375). Nesta, a autora conta a história de um homem que transformou um quati em cachorro, deixando o pequeno animal confuso quanto sua raça. A autora pediu também para que não julgassem o pobre homem carente, mas isso não impediu que a mesma recebesse uma carta de um leitor dando uma outra versão para a história que ela havia contado. Tamanho foi o entusiasmo de Clarice com o que recebeu que, quase um mês depois, ela resolveu publicar na íntegra a contribuição de seu leitor em pleno Jornal do Brasil.

A postura de adotar o fazer COM o outro nos permite entender que 0 pesquisador ou Clarice abrem mão de uma posição acima dos atores/leitores, uma posição de saber privilegiado, pois para estar com o outro é necessário dialogar de forma a se interessar pelos interesses do outro e a estes formular perguntas interessantes. $E$, nessa condução entender que estar no campo, estar com o outro é não estar imune a afetações tão características destes encontros. Diferente de uma postura de assepsia, o pesquisador cujo pesquisar baseia-se nos pressupostos da Teoria ator-rede entende a riqueza do outro no campo e quão enriquecedor é o diálogo com o mesmo. Isso pode incluir mal entendidos, é arriscado, o pesquisador pode ver seu projeto posto em cheque, mas nada disso faz perder sua validade. Entre recalcitrâncias e mal entendidos há um pesquisador, um campo, os atores, mostrando a heterogeneidade da rede.

Ao recrutar o leitor, Clarice o torna coparticipante de sua obra que, nesse sentido, pode ser reinventada a todo instante. Tal e qual um pesquisador que não está em busca da verdade, mas está sensível e receptivo aos efeitos de suas ações, ela nos diz:

Não creio em soluções nem em explicações absolutas. Creio, isso sim, na interpretação de cada leitor. Em minha opinião, um livro - ou um quadro, ou uma melodia, ou um filme - não deveria passar despercebido. Eu quero que cada um entre no relato, no conflito. E que a partir dali, encare de uma maneira 
pessoal o que escrevi a minha maneira. Entende? (Rocha, 2011, p.119).

Em seu modo de escrever dialogando com o leitor, além de permitir que este se sinta a vontade para interferir em sua escrita, ela nos ajuda a pensar um bom modo de escrever na TAR - um texto criado a partir de práticas e que seja por si mesmo uma prática que engendre outras práticas.

Em sua crônica, Como é que se escreve?, a autora nos indica sua despreocupação em agradar críticos por não perseguir um rigor técnico em seus escritos; apenas não quer seguir o que esperam dela, seja coerência ou enredos lógicos, bem acabados simplesmente escreve procurando criar versões de realidade:

Quando não estou escrevendo, eu simplesmente não sei como se escreve. E se não soasse infantil e falsa a pergunta das mais sinceras, eu escolheria um amigo escritor e lhe perguntaria: como é que se escreve?

Por que, realmente, como é que se escreve? que é que se diz? e como dizer? e como é que se começa? e que é que se faz com o papel em branco nos defrontando tranquilo?

Sei que a resposta, por mais que intrigue, é a única: escrevendo. Sou a pessoa que mais se surpreende de escrever. E ainda não me habituei a que me chamem de escritora. Porque, fora das horas em que escrevo, não sei absolutamente escrever. Será que escrever não é um ofício? Não há aprendizagem, então? O que é? Só me considerarei escritora no dia em que eu disser: sei como se escreve. (Lispector, 1999, pp. 156-157)

\section{Tecendo redes (e textos) entre humanos e não humanos}

Mesmo em seus textos escritos para o Jornal do Brasil, Clarice não se reduzia ao fato - narrava dando vida ao que estava sendo encenado. Tudo o que se passa no texto, todos ali - humanos e não humanos compõem um cenário em que ora um se destaca, ora outro, numa alternância não excludente entre figuras e fundo, actantes e atuados em mútua constituição. Independentemente de quem está fazendo, importa o que está sendo feito e o que isso faz fazer. Lendo Clarice, vamos vendo surgir realidades distintas a partir das afetações produzidas nos encontros entre diferentes. Clarice fala de suas obras como comprometidas com o mundo e produtoras de mundos e, utilizando a terceira pessoa do singular, dá a dimensão deles como actantes: "Os meus livros não se preocupam com os fatos em si, mas com a repercussão deles nos indivíduos. Isso tem muita importância 
para mim. É o que faço. Acho que sob esse ponto de vista, eu também faço livros comprometidos com o homem e a realidade não é fenômeno puramente externo." (Rocha, 2011, p. 83). Mais adiante, na mesma página, ela mesma nos fala de como se inspira: "Entre mim e o papel da máquina de escrever não deve existir interferência de espécie alguma." Aqui fica clara sua relação direta, sua parceria com os não humanos na produção de textos que também evidenciam encontros entre humanos e não humanos criando mundos. $O$ ato da escrita não está centrado apenas nela, enquanto a autora, mas se trata de um trabalho em conjunto com seus parceiros: papel e a máquina de escrever.

Os livros, segundo ela: "O que sinto é que um livro, uma vez terminado, passa a ter vida própria. É como o filhote de um animal. A realização de um livro, seja qual for o conteúdo - de um conto, ou de todo um romance - sempre é algo doloroso. Um processo angustiante. terminado este sofrimento, ou seja, consumado o parto, quero que o livro saia por aí, que se vire." (Rocha, 2011, p. 116). Aqui temos uma ilustração de um bom modo de falar da relação de mútua afetação entre diferentes actantes na TAR - ambos atuam e são atuados. O livro é escrito e ganha vida própria; transforma e se transforma, é do mundo e cria mundos ao produzir afetações.

Clarice ilustra com muita precisão a perspectiva da simetria entre diferentes que temos na TAR, ao provocar a instabilidade no que parece conhecimento pronto, verdade universal:

"Um dia desses eu estava numa fazenda e o fazendeiro que falava sobre seus próprios problemas, e disse: 'Porque é claro que um bezerro reconhece a mãe. Ela só dá leite para o seu bezerro.' E eu então disse: 'Não é claro, não. Isso não é natural, não.' Mas ele espantou-se: 'Como é que não é natural?' 'É um fato formidável! Você já pensou no que uma vaca pensa?' Aí o homem estatelou-se todo, coitado. Mudou de assunto na mesma hora... Mas que elas reconhecem, reconhecem. (p. 162)

A capacidade de Clarice de estar no mundo e se conectar com o que está no seu campo de interesses se faz pela sensibilidade. Assim, ela consegue criar versões de mundo que perpassam a dança do observar com o sentir, performando uma realidade que nos afeta por revelar a riqueza de um cotidiano que, não raro, se torna invisível pelo domínio da racionalidade. Por suas mãos, o sensível cresce e se arranja com a maestria de sua escrita e de seu dizer.

Para finalizar, deixemos que Clarice traduza a si mesma. Entrevistando-a, Hohlfeldt descreve o processo de criação, descrição com a qual ela concordou: 'A crônica, contudo, nasce do papel e da máquina de escrever, ao sabor do teclado.' (Hohlfeldt, como citado 
por Rocha, 2011, p.60). Segunda ela própria, "Não sei classificar a minha obra. Em cada livro eu renasço." (Rocha, 2011, p.86).

\section{Referências}

Despret, V (2011). Leitura Etnopsicológica do segredo. Dossiê Despret. Revista Fractal de Psicologia, 23(1), 5-28.

Despret, V. (2004). Our Emotional Makeup - ethnopsychology and selfhood. New York: Other Press.

Latour, B. (2008). Reensamblar lo social: uma introdución a la teoria del actor-red. (G. Zadunaisky, trad.), Buenos Aires: Manantial. (Reassembling the Social - An Introduction to Actor-Network Theory em 2005).

Latour, B. (2000). Ciência em ação: como seguir cientistas e engenheiros sociedade afora. (Benedetti, I. C., Trad.) São Paulo: UNESP, 2000.(Science in Action, 1998)

Latour, B. (2000). Ciência em ação: como seguir cientistas e engenheiros sociedade afora. (Benedetti, I. C., Trad.) São Paulo: UNESP, 2000. (Science in Action, 1998)

Latour, B. (1994). Jamais fomos modernos: Ensaio de Antropologia Simétrica. (C. I, Costa, Trad.) Rio de Janeiro: Editora34. (Nous n`avons jamais eté modernes em 1994)

Law, J. (2004) After Method: Mess in social science research. New York: Roultledge.

Law, J, \& Urry, J. (2005) Enacting the social. Economy and Society, $3(3), 390-410$.

Lispector, C. (1999) A Descoberta do Mundo. Rio de Janeiro: Editora Rocco LTDA.

Mol, A. (2008) The logical of care: Health and the problem of patient choice. London: Routledge.

Mol, A (2007). Política ontológica. Algumas idéias e várias perguntas. In J. A. Nunes, \& R. Roque (Orgs.). Objectos impuros: experiências em estudos sociais da ciência (pp.22-40). Porto: Edições Afrontamento.

Moraes, M. (2010). PesquisarCOM, Política Ontológica e deficiência visual. In M. Moraes, \& V. Kastrup (Org). O Exercício de ver e não ver (pp. 26-51). Rio de Janeiro: Nau.

Moraes, M. (2003). Alianças para uma Psicologia em Ação: sobre a noção de rede. Recuperado em 24 de setembro, 2009, de www.necso.ufrj.br/Ato2003/MarciaMoraes.htm

Quadros, L. C. T.(2011). A construção artesanal do fazer clínico em Psicologia. Tese de doutorado, Programa de Pós-graduação em Psicologia Social da UERJ, Rio de Janeiro, RJ, Brasil.

Rocha, E. (2011). Clarice Lispector. Série Encontros. Rio de Janeiro: Beco do Azougue, 
Stengers, I. (1989). A Ciência no Feminino. Revista 34 Letras, (5/6), 427-431.

\section{Endereço para correspondência \\ Débora Emanuelle Nascimento Lomba}

Universidade do Estado do Rio de Janeiro

Programa de Pós Graduação em Psicologia Social

Rua São Francisco Xavier, 524, $10^{\circ}$ andar sala 10.009 bloco F, Maracanã, CEP 20550-013, Rio de Janeiro, RJ, Brasil

Endereço eletrônico: debora_lomba@yahoo.com.br, deboralomba@gmail.com

\section{Laura Cristina de Toledo Quadros}

Universidade do Estado do Rio de Janeiro

Programa de Pós Graduação em Psicologia Social

Rua São Francisco Xavier, 524, $10^{\circ}$ andar sala 10.009 bloco F, Maracanã, CEP 20550-013, Rio de Janeiro, RJ, Brasil

Endereço eletrônico: lauractq@gmail.com

\section{Luciana Loyola Madeira Soares}

Universidade do Estado do Rio de Janeiro

Programa de Pós Graduação em Psicologia Social

Rua São Francisco Xavier, 524, $10^{\circ}$ andar sala 10.009 bloco F, Maracanã, CEP 20550-013, Rio de Janeiro, RJ, Brasil

Endereço eletrônico: psi.lucianasoares@gmail.com

Recebido em: 03/06/2014

Reformulado em: 27/10/2014

Aceito para publicação em: 07/11/2014

\section{Notas}

* Coordenadora da Equipe de Psicologia - Instituto BEM; Mestranda - PPGPS UERJ, RJ, RJ, Brasil.

** Professora visitante do Instituto de Psicologia e do Programa de Pós Graduação em Psicologia Social UERJ, Rio de Janeiro, RJ, Brasil; Doutora em Psicologia Social PPGPS- UERJ; Mestre em Psicologia Social e da Personalidade ISOP/FGV/UFRJ; Especialista em Psicologia Clínica CRP; Vice-coordenadora do projeto de extensão Laboratório Gestáltico: Configurações e práticas contemporâneas. Psicóloga - UFRJ, RJ, RJ - CRP: 05/12561.

*** Professora da graduação em Psicologia do Instituto Brasileiro de Medicina de Reabilitação - RJ, RJ, Brasil. Supervisora de estágio em Psicologia Clínica da graduação em Psicologia do Centro Universitário Celso Lisboa - RJ, RJ, Brasil. Membro do Laboratório gestáltico UERJ - Configurações e Práticas Contemporâneas, RJ, RJ, Brasil. Doutoranda - PPGPS UERJ, RJ, RJ, Brasil. Mestre - Universidade Veiga de Almeida, RJ, RJ, Brasil. Especialista em Psicologia Clínica e Educacional Conselho Regional de Psicologia 05, RJ, RJ, Brasil. Especialista em Saúde Mental Infanto Juvenil - Pontifícia Universidade Católica, RJ, RJ, Brasil. Psicóloga - UERJ

${ }^{1}$ Ver: Moraes, M. (2010)

2 Referência a personagens das obras de Clarice Lispector, em: A Hora da Estrela, A paixão segundo G.H, e A vida íntima de Laura, respectivamente.

${ }^{3}$ Ver V. Despret, 2004 